\title{
Consumo, Digestibilidade e Desempenho de Novilhos Alimentados com Rações à Base de Feno de Capim-Tifton 85, em Diferentes Idades de Rebrota ${ }^{1}$
}

\section{Josvaldo Rodrigues Ataíde Júnior ${ }^{2}$, Odilon Gomes Pereira ${ }^{3}$, Sebastião de Campos Valadares Filho ${ }^{3}$, Rasmo Garcia ${ }^{3}$, Paulo Roberto Cecon ${ }^{4}$, Marcos José Alves ${ }^{2}$, Andréa Luciane Moreira ${ }^{5}$}

RESUMO - Objetivou-se avaliar o consumo e as digestibilidades aparentes de matéria seca (MS), proteína bruta (PB), extrato etéreo (EE), carboidratos totais (CT) e fibra em detergente neutro (FDN), o ganho de peso e a conversão alimentar em bovinos Nelore, recebendo rações contendo feno de capim-tifton 85 com 35, 42 e 56 dias de rebrota. Foram utilizados 18 novilhos, não-castrados, com peso vivo médio inicial de $345 \mathrm{~kg}$, distribuídos em um delineamento em blocos casualizados, com seis repetições. Todas as rações continham $60 \%$ de volumoso e $40 \%$ de mistura concentrada constituída por fubá de milho e minerais, na base da matéria seca. O experimento teve duração de 100 dias, 16 dias de adaptação e três períodos de 28 dias para a avaliação do desempenho. O avanço da idade de rebrota do capimtifton 85 produziu comportamento linear decrescente para consumos de MS, PB e EE, enquanto os consumos de CT e FDN não foram afetados pela idade de rebrota. O ganho médio diário de peso $(1,23 \mathrm{~kg})$ e a conversão alimentar $(6,35)$ não foram influenciados pela idade de rebrota. Os coeficientes de digestibilidade de MS $(59,6)$, PB $(48,0)$, EE (53,2), CT (63,6) e FDN $(41,5)$ também não foram influenciados pela idade de rebrota do feno de capim-tifton 85 . Embora as dietas utilizadas sejam eqüivalentes nutricionalmente, recomenda-se a idade de corte de 42 dias de rebrota.

Palavras-chave: conversão alimentar, ganho de peso

\section{Intake, Digestibility and Performance of Steers Fed Diets Containing Tifton-85 Bermudagrass Hays at Different Regrowth Ages}

\begin{abstract}
Intake and apparent digestibilities of dry matter (DM), crude protein (CP), ether extract (EE), total carbohydrates (TC) and neutral detergent fiber (NDF), average daily weight gain and feed: gain of diets containing Tifton 85 bermudagrass hays with 35,42 and 56 days of regrowth were evaluated with Nellore steers. Eighteen animals averaging $345 \mathrm{~kg}$ were allotted in a randomized complete blocks design with six replicates. All diets contained $60 \%$ forage and $40 \%$ of a concentrate mix based on ground corn and minerals, in dry matter basis. The experiment lasted 100 days, in which 16 were used for the animal adaptation and three periods of 28 days for the animal performance evaluation. As the hay age increased, there was a linear decrease in DM, CP and EE intake, while the TC and NDF intakes were not affected by the regrowth age. The average daily weight gain $(1.23 \mathrm{~kg})$ and the feed: gain (6.35) was not influenced by the regrowth age. The coefficients of digestibility of DM (59.6), CP (48.0), EE (53.2), TC (63.6) and NDF (41.5) were not affected by the regrowth age of the Tifton 85 bermudagrass hay. Although the diets were nutritionally similar, the recommendation for the regrowth age was 42 days.
\end{abstract}

Key Words: feed:gain ratio, weight gain

\section{Introdução}

A bovinocultura de corte constitui-se no maior segmento da economia rural brasileira, tendo, neste contexto, relevante papel social, tanto por gerar empregos, como por se constituir na principal fonte de proteína animal da dieta da população do país (NOGUEIRA NETTO, 1996).

A baixa produtividade da pecuária de corte, em muitos sistemas de exploração, tem sido significativamente alterada pela intensificação da produção, com a introdução de tecnologias que visam oferecer condições sanitárias, de manejo e de alimentação mais adequadas, buscando, assim, a melhoria da produtividade animal sobre bases econômicas.

A estacionalidade da produção de forragem é reconhecida como um dos principais fatores responsáveis pelos baixos índices de produtividade da pecuária nacional, visto que os níveis de produção animal obtidos durante a seca são comprometidos pelo baixo rendimento forrageiro nesta época.

\footnotetext{
${ }^{1}$ Parte da Tese de Mestrado do primeiro autor apresentada à UFV. Pesquisa parcialmente financiada pela FAPEMIG

2 Zootecnista, MSc. E.mail: josvaldo@brasmail.com.br

3 Professor DZO/UFV. Bolsista do CNPq. E.mail: odilon@mail.ufv.br

${ }^{4}$ Professor DPI/UFV. Bolsista do CNPq.

5 Zootecnista, Estudante de Doutorado/UNESP
} 
Para manter altos índices de produção e resolver os problemas causados pela deficiência alimentar, é fundamental a adoção de técnicas capazes de garantir o aproveitamento de toda a forragem produzida no período chuvoso, utilizando-a posteriormente para suplementação no período seco. A fenação é apontada como uma das alternativas para solucionar este problema.

A qualidade do feno está associada a fatores relacionados com as plantas a serem fenadas, às condições climáticas durante a secagem a campo e ao sistema de armazenamento empregado (REIS, 1996).

O capim-tifton 85 é uma forrageira com bom índice de produtividade e tem características morfológicas propícias para fenação (HADDAD e CASTRO, 1998), que garantem eficiente desidratação do material, assim como manutenção do valor nutritivo do feno desta gramínea.

A qualidade das plantas forrageiras influencia a produtividade animal, já que o espaço ocupado pelos materiais fibrosos ou volumosos e o tempo de permanência destes materiais no rúmen são aumentados com a maturação da planta, podendo alterar a dinâmica da fermentação ruminal, como também a velocidade de passagem do alimento por este compartimento (RODRIGUES, 1998).

Com a maturidade da planta, a produção de componentes potencialmente digestíveis, como os carboidratos solúveis e as proteínas, tende a diminuir, e os constituintes da parede celular, a aumentar, sendo esperados, conseqüentemente, declínios na digestibilidade e no consumo. Segundo VAN SOEST (1965), o consumo de alimentos está inversamente relacionado com o teor de fibra em detergente neutro (FDN), em dietas que contêm mais de 60\% de FDN, e a parede celular é o constituinte da planta que tem a mais estreita relação com o consumo voluntário.

De acordo com NORTON (1982), com o avanço da idade fisiológica das plantas, ocorre substituição do conteúdo celular por parede celular, assim como transformação da parede, devido ao surgimento da parede secundária, havendo maior participação de celulose e lignina. Além disso, inicia-se o processo de senescência, que acelera ainda mais o aumento do teor de fibra.

Segundo VAN SOEST (1994), a digestibilidade é uma descrição qualitativa do consumo, expressa pelo coeficiente de digestibilidade, que indica a quantidade percentual de cada nutriente do alimento que o animal tem condição de utilizar.

A digestibilidade dos nutrientes dos alimentos de bovinos em pastejo, ou em confinamento, pode ser estimada por meio de indicadores internos, presentes nos alimentos e nas fezes. O método se baseia no fato de que, à medida que o alimento transita pelo trato gastrointestinal, a concentração do indicador aumenta progressivamente, pela remoção de outros componentes por digestão e absorção (ASTIGARRA, 1997). Nesse contexto, a fibra indigestível em detergente neutro ou ácido, após 144 horas de incubação in vitro ou in situ, tem sido largamente utilizada em estudos de digestibilidade (COCRHAN et al., 1986; LIPPKE, et.al., 1986; BERCHIELLI et al., 1996).

Por se tratar de uma forrageira recém introduzida no Brasil, pouco se conhece sobre as qualidades nutricionais e as respostas dos animais, quando alimentados com capim-tifton 85. Diante do exposto, objetivou-se com o presente trabalho, avaliar os consumos e as digestibilidades aparentes de MS, PB, EE, CT e FDN, o ganho de peso e a conversão alimentar de bovinos Nelore, não-castrados, alimentados com dietas à base de feno de capim-tifton 85 , com diferentes idades de rebrota.

\section{Material e Métodos}

O experimento foi conduzido no Parque de Exposição Agropecuária do Município de Tupaciguara, Minas Gerais. A cidade de Tupaciguara está localizada no Triângulo Mineiro, a 890 m de altitude, 18³5'34" de latitude sul e $48^{\circ} 42^{\prime} 16^{\prime \prime}$ de longitude oeste (INSTITUTO DE GEOCIÊNCIAS APLICADAS/FUNDAÇÃO CENTRO TECNOLÓGICO DE MINAS GERAIS - IGA/CETEC, 1993).

Os fenos de capim-tifton 85 foram produzidos na Fazendas Prado, no Município de Tupaciguara, no período de janeiro a março de 1997, após receberem adubação com $75 \mathrm{~kg} /$ ha de $\mathrm{N}$, na forma de sulfato de amônio, e $60 \mathrm{~kg} / \mathrm{ha} \mathrm{de} \mathrm{K}_{2} \mathrm{O}$, como cloreto de potássio.

Utilizaram-se 18 bovinos Nelore, não-castrados, com peso vivo médio inicial de $345 \mathrm{~kg}$, distribuídos em um delineamento em blocos casualizados, com três tratamentos e seis repetições, usando o critério de peso para a distribuição dos animais.

Os animais foram pesados, vermifugados e distribuídos em baias individuais de $12 \mathrm{~m}^{2}$, com cocho coberto e bebedouro automático. As pesagens foram efetuadas no início e final do experimento, sem jejum prévio, realizando-se pesagens intermediárias a cada 28 dias, num total de 84 dias experimentais, após 16 dias de adaptação às dietas.

As dietas foram compostas por feno de capimtifton 85 , produzido com 35,42 e 56 dias de 
rebrota e concentrado, adotando-se relação volumoso:concentrado de 60:40\%, na base da matéria seca (MS). O concentrado foi constituído por fubá de milho e mistura mineral. As dietas foram calculadas segundo o NATIONAL RESEARCH COUNCIL NRC (1996), de modo a atenderem as exigências para obtenção de $1 \mathrm{~kg}$ de ganho médio diário. $\mathrm{Na}$ Tabela 1, são apresentadas as composições bromatológicas do concentrado e dos fenos de capimtifton 85, com 35, 42 e 56 dias de rebrota. Consta da Tabela 2 a composição bromatológica das rações experimentais.

A alimentação foi fornecida diariamente, às 7 e $15 \mathrm{~h}$, permitindo-se sobras em torno de $10 \%$ do oferecido. Durante o experimento, coletaram-se amostras dos alimentos fornecidos e das respectivas sobras, as quais foram identificadas e acondicionadas em freezer, para posteriores análises laboratoriais.

Entre o $42^{\circ}$ e $49^{\circ}$ dia experimental, realizaram-se coletas de fezes, de aproximadamente $150 \mathrm{~g}$, diretamente no piso, antes da primeira alimentação dos animais, para a estimativa da produção fecal, utilizando-se a fibra em detergente ácido indigestível (FDAI) como indicador. Neste período, também foram coletadas

Tabela 1 - Teores de matéria seca (MS), matéria orgânica (MO), proteína bruta (PB), extrato etéreo (EE), carboidratos totais (CT) e fibra em detergente neutro (FDN), do concentrado e dos fenos de capim-tifton 85, em diferentes idades de rebrota

Table 1 - Contents of dry matter (DM), organic matter $(O M)$,crude protein $(C P)$, ether extract $(E E)$, total carbohydrates (TC) and neutral detergent fiber (NDF) of the concentrate and of the tifton 85 bermudagrass hays, at different regrowth ages

\begin{tabular}{lcccc}
\hline Item & \multicolumn{3}{c}{$\begin{array}{c}\text { Feno (dia) } \\
\text { Hay (day) }\end{array}$} & $\begin{array}{c}\text { Concentrado } \\
\text { Concentrate }\end{array}$ \\
\cline { 2 - 4 } & 35 & 42 & 56 & \\
\hline MS (\%) & 87,8 & 88,0 & 87,6 & 87,5 \\
$D M(\%)$ & & & & \\
MO $^{1}$ & 92,3 & 92,9 & 92,7 & 97,5 \\
$O M$ & 17,1 & 14,6 & 12,2 & 9,8 \\
PB $^{1}$ & 1,62 & 1,35 & 1,31 & 3,78 \\
$C P$ & 73,6 & 76,9 & 79,2 & 83,9 \\
EE $^{1}$ & & & & 14,9 \\
$\mathrm{CT}^{1}$ & 77,9 & 77,7 & 80,5 & \\
$T C$ & & & & \\
FDN & & & & \\
$N D F$ & & &
\end{tabular}

amostras dos alimentos fornecidos e das sobras. As amostras de fezes, alimentos e sobras, referentes à estimativa da digestibilidade, foram incubadas in vitro, por um período de 144 horas, à temperatura de $39^{\circ} \mathrm{C}$, segundo metodologia descrita por COCHRAN et al. (1986). O material oriundo de cada incubação foi submetido à digestão com detergente ácido, para estimativa da FDAI.

Todas as amostras foram pré-secas em estufa ventilada a $65^{\circ} \mathrm{C}$ e, posteriormente, moídas em moinho tipo "Willey" com peneira de 30 mesh. A seguir, foram acondicionadas em frascos identificados, para determinação de MS, FDN, PB e EE, segundo SILVA (1990).

Os carboidratos totais (CT) dos alimentos fornecidos, das sobras e das fezes e o consumo de nutrientes digestíveis totais (NDT) foram calculados segundo SNIFFEN et al. (1992), em que $\mathrm{CT}(\%)=100-(\% \mathrm{~PB}+\% \mathrm{EE}+\%$ Cinzas $)$ e NDT $(\mathrm{kg})=$ $(\mathrm{PB}$ ing. - PB fecal $)+2,25$ (EE ing. - EE fecal $)+$ (CT ing. - CT fecal).

Os resultados foram interpretados estatisticamente por meio de análises de variância e regressão, utilizando-se o Sistema de Análises Estatísticas e Genéticas - SAEG (UNIVERSIDADE FEDERAL DE VIÇOSA - UFV, 1995). A escolha do modelo baseou-se na significância dos coeficientes de regressão, utilizando-se o teste " $t$ " de Student, em nível de $10 \%$ de probabilidade, e no coeficiente de determinação.

\section{Resultados e Discussão}

Na Tabela 3, são apresentados os consumos de MS, PB, EE CT, FDN e NDT, o ganho de peso médio diário e a conversão alimentar. Observa-se que apenas os consumos de MS, PB e EE, quando expressos em kg/dia, foram influenciados pela idade de rebrota dos fenos nas rações. Reduções de 0,03704 ; 0,01434; e $0,00139 \mathrm{~kg} /$ dia foram estimadas para os respectivos nutrientes, para cada dia de avanço na idade do feno.

Diminuição no consumo de matéria seca, em função da idade dos fenos nas dietas, pode está relacionada ao aumento da parede celular indigerível dos mesmos, com o avanço da maturidade da planta. HENRIQUES et al. (1998), avaliando a degradabilidade dos fenos usados neste estudo, observaram, após 144 horas de incubação ruminal, valores de FDN indigestível de 18,4;21,1; e 28,9\%, respectivamente, para fenos com 35, 42 e 56 dias de rebrota.

RIBEIRO et al. (1998), avaliando as mesmas 
Tabela 2 - Teores de matéria seca (MS), matéria orgânica (MO) proteína bruta (PB), extrato etéreo (EE), carboidratos totais (CT), fibra em detergente neutro (FDN) e nutrientes digestíveis totais (NDT) das rações contendo $60 \%$ de feno de capimtifton 85 em diferentes idades de rebrota

Table 2 - Contents of dry matter (DM), organic matter (OM), crude protein $(C P)$, ether extract $(E E)$, total carbohydrates (TC), neutral detergent fiber (NDF) and total digestible nutrients (TDN) of the diets with $60 \%$ tifton 85 bermudagrass hay, at different regrowth ages

\begin{tabular}{lccc}
\hline Item & \multicolumn{3}{c}{$\begin{array}{c}\text { Idade (dia) } \\
\text { Age (day) }\end{array}$} \\
\cline { 2 - 4 } & 35 & 42 & 56 \\
\hline MS (\%) & 87,6 & 87,8 & 87,5 \\
$D M$ & & 94,7 & 94,6 \\
MO $^{1}$ & 94,4 & 12,7 & 11,3 \\
$O M$ & 14,2 & 2,32 & 2,30 \\
PB $^{1}$ & 2,48 & 79,7 & 81,1 \\
$C P$ & 77,7 & 52,6 & 54,3 \\
EE $^{1}$ & 52,7 & 62,0 & 58,2 \\
$T C$ & & & \\
FDN $^{1}$ & 58,9 & & \\
$N D F$ & & &
\end{tabular}

$1 \%$ na MS (\% in DM).

dietas usadas neste estudo, inclusive uma quarta dieta, contendo feno de capim-tifton 85, com 28 dias de rebrota, em ensaio com animais zebuínos fistulados no rúmen e no abomaso, registraram resposta quadrática da idade do feno para o consumo de MS, estimando consumo máximo em dietas contendo feno com 41 dias de idade. Resultados semelhantes foram observados por ATAÍDE JR. et. al.(1998), que, ao fornecerem estes fenos a ovinos, como fonte única de alimentos, encontraram resposta quadrática para o consumo de matéria seca em função da idade, estimando máximo consumo aos 39 dias de rebrota.

Por outro lado, HILL et al. (1998), avaliando fenos dos capins coastal, tifton-78 e tifton 85 , colhidos aos 28 e 42 dias de crescimento, em ensaio de digestibilidade com bovinos, não verificaram efeito da idade de crescimento para consumo de matéria orgânica.

Influência da idade do feno também foi observada para os consumos de PB e EE, que pode ser explicada pela diminuição destes nutrientes nas dietas, com o avanço da idade dos fenos, ou pela redução no consumo de matéria seca.

Os consumos de CT e NDT não foram afetados pela idade de rebrota dos fenos, apresentando valores médios de 6,1 e $5,75 \mathrm{~kg} / \mathrm{dia}$.

$\mathrm{O}$ consumo de FDN, expresso em \% do PV, não foi afetado pela idade de rebrota dos fenos incluídos nas dietas, estimando-se valor médio de 0,97. Este resultado se assemelha ao obtido por RIBEIRO et al. (1998), que registraram consumo médio de FDN de 0,98\% do PV; valores próximos ao estabelecido por Mertens, 1988, citado por SNIFFEN (1988), que encontrou valor de 1,2 \% do PV para ingestão de FDN na ração, chegando ao valor de $1 \%$, para animais em crescimento. $O$ referido autor relatou que valores acima dos citados anteriormente implicariam em restrição da ingestão, pelo efeito do enchimento do rúmen-retículo.

Quanto ao ganho de peso médio diário, não foi detectado efeito da idade de rebrota dos fenos de capim- tifton 85 nas rações, registrando-se valores médios diários de 1,37; 1,10; e 1,20 kg/animal, para as dietas contendo fenos com 35, 42 e 56 dias, respectivamente. Comportamento similar foi observado para a conversão alimentar, cujo valor médio obtido foi de 6,35.

Os consumos de MS, PB e NDT preditos pelo NRC (1984), para um bovino não-castrado com peso vivo de $408 \mathrm{~kg}$ e ganho de peso vivo diário de $1,13 \mathrm{~kg}$, foram 9,$2 ; 0,89$ e $6,45 \mathrm{~kg} / \mathrm{dia}$, respectivamente. Os valores observados variaram de 7,26 a $8,13 \mathrm{~kg} / \mathrm{dia}$ para o consumo de MS; 0,82 a 1,14 para o consumo de PB; e 5,07 a 6,28 para o consumo de NDT, encontrando-se próximos aos valores preditos pelo referido sistema.

Na Tabela 4, são apresentados os coeficientes de digestibilidade de MS, PB, EE, CT e FDN, observando-se que as digestibilidades não foram afetadas pela idade dos fenos incluídos nas rações. RIBEIRO et al. (1998) também não detectaram efeito da idade dos fenos de capim-tifton 85 , com de 28, 35, 42 e 56 dias de rebrota, sobre os coeficientes de digestibilidade dos nutrientes das rações. Todavia, os valores registrados por esses autores foram superiores aos observados neste trabalho.

Uma possível explicação para os menores coeficientes de digestibilidades dos nutrientes das rações, neste estudo, seria a baixa recuperação do indicador interno FDA indigestível, nas fezes, conforme sugerem COCHRAM et al. (1986). De fato, esses autores, ao avaliarem a relação entre a digestibilidade in vivo (coleta total de fezes) da matéria seca e aquelas estimadas pelos indicadores FDA e FDN indigestíveis, verificaram alta variabilidade entre as digestibilidades dos alimentos testados. Contudo, BERCHIELLI et 
Rev. bras. zootec.

Tabela 3 - Médias, equações de regressão ajustadas (ER), coeficientes de determinação $\left(r^{2}\right)$ e de variação (CV\%) para os consumos de matéria seca (CMS), proteína bruta (CPB), extrato etéreo (CEE), carboidratos totais (CCT), fibra em detergente neutro (CFDN) e nutrientes digestíveis totais (CNDT), ganho médio diário de peso vivo (GMDPV) e conversão alimentar (CA), em função da idade de rebrota (I) do feno de capim-tifton 85

Table 3 - Means, fitted regression equations (RE), coefficients of determination $\left(r^{2}\right)$ and variation (CV) for the intakes of dry matter (DMI), crude protein (CPI), ether extract (EEI), total carbohydrates (TCI), neutral detergent fiber (NDFI) and total digestible nutrients (TDNI), average daily weight gain (ADWG) and feed:gain ratio (F:G), on tifton 85 bermudagrass hay regrowth ages

\begin{tabular}{|c|c|c|c|c|c|c|}
\hline \multirow[t]{2}{*}{ Item } & \multicolumn{3}{|c|}{$\begin{array}{c}\text { Idade (dia) } \\
\text { Age (day) }\end{array}$} & \multirow[t]{2}{*}{$\mathrm{ER}(R E)$} & \multirow[t]{2}{*}{$\mathrm{r}^{2}$} & \multirow[t]{2}{*}{$\mathrm{CV}(\%)$} \\
\hline & 35 & 42 & 56 & & & \\
\hline $\begin{array}{l}\text { CMS (kg/dia) } \\
D M I(\text { kg/day })\end{array}$ & 8,13 & 7,44 & 7,26 & $\hat{\mathrm{Y}}=9,25457-0,03704 * * * \mathrm{I}$ & 0,76 & 9,6 \\
\hline $\begin{array}{l}\text { CMS (\% PV) } \\
D M I(\% L W)\end{array}$ & 1,93 & 1,92 & 1,86 & $\hat{\mathrm{Y}}=1,90$ & - & 8,0 \\
\hline $\begin{array}{l}\text { CMS }\left(\mathrm{g} / \mathrm{kg}^{0,75}\right) \\
\text { DMI }(\mathrm{g} / \mathrm{kg} \cdot 75)\end{array}$ & 87,31 & 84,89 & 82,46 & $\hat{Y}=84,89$ & - & 7,8 \\
\hline $\begin{array}{l}\text { CPB (kg/dia) } \\
C P I(k g / d a y)\end{array}$ & 1,14 & 0,93 & 0,82 & $\hat{\mathrm{Y}}=1,59798-0,01434 * \mathrm{I}$ & 0,88 & 8,9 \\
\hline $\begin{array}{l}\mathrm{CEE}(\mathrm{kg} / \mathrm{dia}) \\
E E I \text { (kg/day) }\end{array}$ & 0,21 & 0,18 & 0,17 & $\hat{\mathrm{Y}}=0,24895-0,00139 * * \mathrm{I}$ & 0,70 & 9,4 \\
\hline $\begin{array}{l}\text { CCT (kg/dia) } \\
T C I \text { (kg/day) }\end{array}$ & 6,38 & 5,99 & 5,93 & $\hat{\mathrm{Y}}=6,10$ & - & 9,7 \\
\hline $\begin{array}{l}\text { CFDN (kg/dia) } \\
N D F I \text { (kg/day) }\end{array}$ & 4,12 & 3,74 & 3,77 & $\hat{\mathrm{Y}}=3,88$ & - & 9,4 \\
\hline $\begin{array}{l}\text { CFDN }(\% \text { PV }) \\
N D F I(\% L W)\end{array}$ & 0,98 & 0,96 & 0,96 & $\hat{\mathrm{Y}}=0,97$ & - & 7,9 \\
\hline $\begin{array}{l}\text { CFDN }\left(\mathrm{g} / \mathrm{kg}^{0,75}\right) \\
\text { NDFI }\left(\mathrm{g} / \mathrm{kg}^{.75}\right)\end{array}$ & 44,24 & 42,58 & 42,80 & $\hat{\mathrm{Y}}=43,20$ & - & 7,6 \\
\hline $\begin{array}{l}\text { CNDT (kg/dia) } \\
T D N I(k g / \text { day })\end{array}$ & 5,90 & 6,28 & 5,07 & $\hat{\mathrm{Y}}=5,75$ & - & 19,5 \\
\hline $\begin{array}{l}\text { GMDPV (kg/dia) } \\
A D W G \text { (kg/day) }\end{array}$ & 1,37 & 1,10 & 1,20 & $\hat{\mathrm{Y}}=1,23$ & - & 16,5 \\
\hline $\begin{array}{l}\text { CA } \\
F: G \\
\end{array}$ & 6,02 & 7,00 & 6,00 & $\hat{\mathrm{Y}}=6,35$ & - & 17,4 \\
\hline
\end{tabular}

Tabela 4 - Médias, equações de regressão (ER) ajustadas e coeficientes de variação (CV) para as digestibilidades de matéria seca (MS), proteína bruta (PB), extrato etéreo (EE), carboidratos totais (CT) e fibra em detergente neutro (FDN), em função da idade de rebrota (I) do capim-tifton 85

Table 4 - Means, fitted regression equations (RE) and coefficients of variation (CV) for the digestibilities of dry matter (DM), crude protein (CP), ether extract (EE), total carbohydrates (TC) and neutral detergent fiber (NDF), on tifton-85 bermudagrass hay regrowth age

\begin{tabular}{|c|c|c|c|c|c|}
\hline \multirow[t]{2}{*}{$\begin{array}{l}\text { Digestibilidade (\%) } \\
\text { Digestibility }\end{array}$} & \multicolumn{3}{|c|}{$\begin{array}{l}\text { Idade (dia) } \\
\text { Age (day) }\end{array}$} & \multirow[t]{2}{*}{$\mathrm{ER}(R E)$} & \multirow[t]{2}{*}{$\mathrm{CV}(\%)$} \\
\hline & 35 & 42 & 56 & & \\
\hline $\begin{array}{l}\text { MS } \\
D M\end{array}$ & 59,7 & 60,2 & 58,9 & $\hat{Y}=59,6$ & 8,0 \\
\hline $\begin{array}{l}\mathrm{PB} \\
C P\end{array}$ & 49,4 & 47,0 & 47,5 & $\hat{\mathrm{Y}}=48,0$ & 18,4 \\
\hline $\begin{array}{l}\mathrm{EE} \\
C T\end{array}$ & 55,5 & 53,0 & 51,0 & $\hat{\mathrm{Y}}=53,2$ & 15,2 \\
\hline $\begin{array}{l}\text { TC } \\
\text { FDN }\end{array}$ & 64,2 & 64,5 & 62,1 & $\hat{\mathrm{Y}}=63,6$ & 7,1 \\
\hline$N D F$ & 42,7 & 42,1 & 39,8 & $\hat{\mathrm{Y}}=41,5$ & 17,5 \\
\hline
\end{tabular}


al. (1996), avaliando diferentes indicadores, em estudos com novilhos $\mathrm{H}^{*} \mathrm{Z}$, em confinamento, observaram que tanto a FDA como a FDN indigestível forneceram valores semelhantes aos obtidos pelo método de coleta total de fezes.

Por outro lado, OLIVEIRA et al. (2000), avaliando o capim-tifton 85 nas idades de 28 a 70 dias de rebrota, observaram resposta quadrática para a digestibilidade in vitro da MS, estimando valor mínimo de $45,4 \%$ aos 65 dias de idade.

Os dados obtidos permitem inferir que as dietas utilizadas foram nutricionalmente similares. Contudo, recomenda-se a produção de feno com este capim até aos 42 dias de rebrota, devido ao maior acúmulo de fibra em detergente neutro indigestível a partir desta idade. Além disso, destaca-se, ainda, que durante o processo de fenação foi observado que as plantas com idade superior a 42 dias de rebrota apresentaram intenso acamamento, dificultando a operacionalidade das máquinas.

\section{Conclusões}

Conclui-se que as dietas utilizadas se eqüivalem nutricionalmente, mas recomenda-se a produção de feno de capim-tifton 85 até os 42 dias de rebrota.

\section{Agradecimento}

A Cézar Prado e Marcos Prado, proprietários da Fazendas Prado, pelo fornecimento do feno e pelo apoio concedido durante a realização desta pesquisa, na cidade de Tupaciguara.

Ao Prefeito de Tupaciguara, Francisco Menezes, por viabilizar a condução do ensaio com bovinos e pelo apoio aos estudantes durante a permanência dos mesmos em Tupaciguara.

Aos Zootecnistas Edvaldo Prudente e Cícero Costa, respectivamente, pelo fornecimento da mistura mineral e produção da ração concentrada.

Ao Sindicato Rural de Tupaciguara, pela gentileza em ceder as instalações do Parque de Exposições (CAPITU).

Ao pecuarista João Divino e família, pela gentileza em ceder os bovinos para realização deste experimento.

À BRASCORDA, pela gentileza em ceder o fio de sisal para o enfardamento.

\section{Referências Bibliográficas}

ASTIGARRA, L. Técnicas para la medición del consumo de rumiantes en pastoreo. In: SIMPÓSIO SOBRE AVALIAÇÃO DE PASTAGENS COM ANIMAIS, 1997, Maringá. Anais... Maringá: UEM, 1997. p.1-23.

ATAÍDE JR., J.R., PEREIRA, O.G., VALADARES FILHO, S.C. et al. Digestibilidade aparente dos nutrientes do feno de tifton-85 (Cynodon spp.) em diferentes idades de rebrota, com ovinos. In: REUNIÃO ANUAL DA SOCIEDADE BRASILEIRA DE ZOOTECNIA, 35, Botucatu, 1998. Anais... Botucatu: SBZ, 1998. p.366-368.

BARRY, M.C., FOX, D.C., TYLUTKY, T.P. et al. 1994. A manual for using the Cornell Net Carbohydrate and Protein System for evaluating cattle diets. Revised for CNCPS release 3 . Ithaca: Cornell University. 40p.

BERCHIELLI, T.T., MAURO, F.R.C., FURLAN, C.L. et al. 1996. Avaliação de indicadores internos para determinação da digestibilidade da matéria seca. In: REUNIÃO ANUAL DA SOCIEDADE BRASILEIRA DE ZOOTECNIA, 33, 1996. Fortaleza. Anais... Fortaleza: SBZ, 1996. v.3. p.44-45.

COCHRAN, R.C., ADAMS, D.C., WALLACE, J.D. et al. 1986. Predicting digestibility of different diets with internal markers: Evaluation of four potential markers. J. Anim. Sci., 63:1476-1483.

HENRIQUES, L.T., PEREIRA, O.G., VALADARES FILHO, S.C. et al. 1998. Degradabilidade "in situ" da matéria seca e da fibra em detergente neutro do feno de tifton-85 (Cynodon spp.), em quatro idades de rebrota. In: REUNIÃO ANUAL DA SOCIEDADE BRASILEIRA DE ZOOTECNIA, 35, Botucatu, 1998. Anais... Botucatu, SBZ, 1998. p.570-572.

HADDAD, C.M., CASTRO, F.G.F. Produção de feno. In: SIMPÓSIO SOBRE MANEJO DA PASTAGEM, Piracicaba, 1998. Anais... Piracicaba: ESALQ-USP, 1998. p.151-172.

HILL, G.M., GATES, R.N., WEST, J.W. Pesquisa com capim bermuda cv. "Tifton 85" em ensaios de pastejo e de digestibilidade de feno com bovinos. In: SIMPÓSIO SOBRE MANEJO DA PASTAGEM, Piracicaba, 1998. Anais... Piracicaba: ESALQ-USP, 1998. p.7-22.

INSTITUTO DE GEOCIÊNCIAS APLICADAS/FUNDAÇÃO CENTRO TECNOLÓGICO DE MINAS GERAIS - IGA/ CETEC. 1993. Secretaria do Estado de Ciência, Tecnologia e Meio Ambiente. Relação das coordenadas, altitudes e declinações magnéticas das sedes dos municípios do Estado de Minas Gerais. Belo Horizonte.

LIPPKE, H., ELLIS, W.C., JACOBS, B.F. 1986. Recovery of indigestible fiber from feces of sheep and cattle on forage diets. J. Dairy Sci., 69(2):403-412.

NATIONAL RESEARCH COUNCIL - NRC. 1984. Nutrients requirements of beef cattle. 6.ed. Washington, D.C. 90p.

NATIONAL RESEARCH COUNCIL - NRC. 1996. Nutrient requirements of beef cattle. 7.ed. Washington: National Academy. 242p.

NOGUEIRA NETTO, V.S. A bovinocultura brasileira em face do mercosul. In: SIMPÓSIO SOBRE MANEJO DA PASTAGEM, 13, Piracicaba, 1996. Anais... Piracicaba: FEALQ, 1996. p.303-318. 
Rev. bras. zootec.

NORTON, B.W. Differences in plant species in forage quality. In: INTERNATIONAL SYMPOSIUM ON NUTRITIONAL LIMITS TO ANIMAL PRODUCTION FROM PASTURES, St. Lucia, 1981. Proceedings... St. Lucia: Farham Royal, Commonwealth Agricultura Bureaux, 1982. p.89-110.

OLIVEIRA, M.A., PEREIRA, O.G., GARCIA, R. et al. 2000. Rendimento e valor nutritivo do capim-tifton 85 (Cynodon spp.) em diferentes idades de rebrota. Rev. bras. zootec., 29(6):1949-1960 (supl. 1).

REIS, R. A. Processamento e conservação de fenos. WORKSHOP SOBRE O POTENCIAL FORRAGEIRO DO GÊNERO Cynodon, 1996, Juiz de Fora. Anais...Juiz de Fora: EMBRAPA-CNPGL, 1996. p.57-68.

RIBEIRO, K.G., GARCIA, R., PEREIRA, O.G. et al. Consumo e digestibilidade aparente dos nutrientes em dietas contendo feno de Tifton 85 de diferentes idades, em bovinos. In: REUNIÃO ANUAL DA SOCIEDADE BRASILEIRA DE ZOOTECNIA, 35, 1998. Botucatu. Anais... Botucatu: SBZ, 1998. p.119-121.

RODRIGUES, M. T. Uso de fibra em rações de ruminantes. In: CONGRESSO NACIONAL DOS ESTUDANTES DE ZOOTECNIA, Viçosa, 1998. Anais... Viçosa: Associação Mineira dos Estudantes de Zootecnia, 1998. p.139-172.

SILVA, D.J. 1990. Análise de alimentos (métodos químicos e biológicos). Viçosa, MG: UFV. 165p.
SNIFFEN, C.J. Balancing ration for carbohydrates for dairy cattle. In: SIMPOSYUM THE APPLICATION OF NUTRITION IN DAIRY PRATICES, 1988, Wayne. Proceedings... Wayne, American Cyanamid Company Agricultural Division, 1988. p.25-35.

SNIFFEN, C.J., O'CONNOR, J.D., VAN SOEST, P.J. et al. 1992. A net carbohydrate and protein system for evaluating cattle diets: II. carbohydrate and protein availability. J. Anim. Sci., 70:3562-3577.

UNIVERSIDADE FEDERAL DE VIÇOSA - UFV. 1995. SAEG-Sistema de análises estatísticas e genética. Viçosa, MG (Apostila).

VAN SOEST, P.J. 1994. Nutritional ecology of the ruminant. 2.ed., Ithaca: Cornell University. 476p.

VAN SOEST, P.J. 1965. Symposium on factors influencing the voluntary intake by ruminants: voluntary intake in relation to chemical composition and digestibility. J. Anim. Sci., 24:834-843.

Recebido em: 23/11/99

Aceito em: 19/10/00 